\title{
GÊNERO ENTRE ESTUDANTES DE TECNOLOGIA BRASILEIROS /AS E ALEMÃES /ÃS: UMA COMPARAÇÃO
}

\author{
A Comparative Study of Gender between \\ Brazilian and German Technology Students \\ Marilia Gomes de Carvalho* \\ Samara Feitosa** \\ Valter Cardoso da Silva***
}

\section{Resumo}

Foi realizada uma pesquisa com alunos do Centro Federal de Educação Tecnológica do Paraná, CEFET - PR, em 2004, e alunos da Fachhochschule Furtwangen - FHF, Alemanha, em 2003, cujo objetivo foi discutir gênero nos cursos da área tecnológica. A pesquisa foi qualitativa e seguiu os mesmos procedimentos no Brasil e na Alemanha. Os resultados da pesquisa trazem temas como: habilidades técnicas $\mathrm{x}$ dependência; a transversalidade do gênero no curso e na profissão; o homem provedor; diferenças de gênero e competência profissional e; gênero e diversidade cultural. Em ambos os países os padrões

* Mestre em Ciências Sociais (Antropologia), pela PUCSP, doutora em Antropologia Social pela USP e pós-doutora em Relações Interculturais pela Université de Technologie de Compiègne - França. Coordenadora do Grupo de Estudos e Pesquisas sobre Relações de Gênero e Tecnologia - GeTec/ PPGTE e professora do Programa de Pós-Graduação em Tecnologia - PPGTE, da UTFPR. (mariliagdecarvalho@gmail.com)

** Mestre em Tecnologia pelo Programa de Pós-Graduação em Tecnologia (PPGTE), da Universidade Tecnológica Federal do Paraná (UTFPR). Professora da Rede Pública do Estado do Paraná. (samarahistoria@yahoo.com.br)

*** Mestre em Tecnologia pelo Programa de Pós-Graduação em Tecnologia (PPGTE), da Universidade Tecnológica Federal do Paraná (UTFPR). Professor da Rede Pública do Estado do Paraná. (prof-valter@hotmail.com) 
tradicionais de gênero estão transformação. O aumento do número de mulheres nestes cursos não tem alterado as relações desiguais de gênero nos dois países.

Palavras-chave: Gênero, Educação tecnológica, Diversidade cultural.

\section{Abstract}

A comparative research study was done involving students from Parana's Federal Technology Education Center - CEFET-PR (Brazil, 2004) and students from the Fachhochschule Furtwangen, FHF (Germany, 2003) with the objective of discussing gender in technology domain courses. The research method was mostly qualitative and the same procedures used in Germany were followed step by step in Brazil. The results of the study brought up to discussion themes such as technical habilities, dependency, gender transversality in the course as well as in the profession, man as "provider", gender differences and professional competency and gender and cultural diversity. In both countries there is an ongoing transformation in the traditional patterns of gender. The increased number of women's enrollments in technological oriented courses did not have an impact in the unequality of gender treatment in both countries.

Keywords: Gender, Technological Education, Cultural Diversity.

O objetivo deste artigo é explorar semelhanças e diferenças que surgiram nas representações dos/as estudantes brasileiros/ as e alemães/ãs relativas ao gênero nos cursos de tecnologia e na profissão. No Brasil o estudo foi feito no antigo Centro Federal de Educação Tecnológica do Paraná, hoje, Universidade Tecnológica Federal do Paraná - UTFPR, nos cursos de Tecnologia em Móveis e Artes Gráficas. Na Alemanha, a pesquisa foi realizada entre alunos e alunas do Curso de Tecnologia em Mídias Digitais da Fachhochschule, em Furtwangen - FHF1.

1 Ver os artigos de CARVALHO et alii e SELKE nesta edição. 
Não se pode negar a importância que os conceitos de cultura, habitus e gênero têm na compreensão das representações e identidades individuais e coletivas ${ }^{2}$. É consenso nas ciências humanas a idéia de que 0 seu objeto de estudo é cultural. Entre as muitas implicações de tal afirmação, pode-se dizer que os indivíduos, apesar de sua base biológica, têm seu comportamento marcado pelas condições sociais do meio. Isto coloca os cientistas sociais diante de um imenso leque de possibilidades que se expressa através de uma multiplicidade de situações e manifestações de comportamentos humanos. Sob esta ótica, a diversidade de práticas sociais constitui o elemento que dá unidade à espécie humana.

Por esta razão, antes de tratar diretamente do tema aqui explicitado, torna-se importante expor algumas características histórico-culturais do Brasil e da Alemanha. Esta breve exposição ajudará o leitor a colocar em perspectiva as diferenças culturais entre estes dois povos que, com certeza, interferem nas representações e práticas sociais relacionadas ao gênero nos cursos de tecnologia dos/ as jovens que participaram deste estudo.

\section{BRASIL E ALEMANHA: BREVE ABORDAGEM HISTÓRICO- CULTURAL ${ }^{3}$}

Uma das muitas formas de apreensão do complexo universo composto pelas várias culturas humanas é a forma como as mesmas se relacionam com a concepção de tempo e espaço e como, a partir desta percepção, organizam a realização de suas tarefas cotidianas (HALL e HALL, 1990).

Para algumas culturas o tempo é apreendido de forma linear, o que leva seus integrantes a se dedicarem a uma única atividade de cada vez. Esta seria a característica de um sistema monocrônico (Tempo M). Segundo Hall e Hall é difícil para os povos que têm a concepção

2 Para efeito de formação de base teórica referente a tais conceitos, reporta-se ao já referido texto de Carvalho et al, desta mesma edição.

3 As informações contidas neste item representam pinceladas superficiais que ajudam a compreender algumas diferenças históricas e culturais entre Brasil e Alemanha. Não se pretendeu absolutamente aprofundar a questão nem tampouco esgotar o tema. 
monocrônica de tempo realizar diversas tarefas ao mesmo tempo ${ }^{4}$. Da mesma forma, estas culturas se caracterizam por uma rigidez com relação ao tempo que dificulta para os indivíduos comportamentos mais flexíveis quanto a horários e estabelecimentos de prazos. De acordo com estas análises, um exemplo de cultura monocrônica seria a alemã.

No entanto, pode-se perceber que outros povos se ocupam de diversas tarefas simultaneamente, isto é, conseguem fazer várias atividades ao mesmo tempo, o que as caracterizaria como um sistema policrônico (Tempo P). Nesta classificação o Brasil, juntamente com outras culturas latinas, seria um exemplo deste tipo de sistema.

Comparação entre sistemas monocrônicos e policrônicos:

\begin{tabular}{|c|c|}
\hline Sistemas Policrônicos & Sistemas Monocrônicos \\
\hline $\begin{array}{c}\text { Faz-se várias coisas ao mesmo } \\
\text { tempo }\end{array}$ & Faz-se uma coisa de cada vez \\
\hline $\begin{array}{c}\text { Admite-se interrupção e mudança } \\
\text { de ocupação }\end{array}$ & $\begin{array}{c}\text { Dedica-se totalmente e } \\
\text { exclusivamente à tarefa assumida }\end{array}$ \\
\hline $\begin{array}{c}\text { Programas e projetos são } \\
\text { freqüentemente e facilmente } \\
\text { modificados }\end{array}$ & $\begin{array}{c}\text { Seguem-se escrupulosamente os } \\
\text { programas estabelecidos }\end{array}$ \\
\hline $\begin{array}{c}\text { A exatidão / pontualidade é muito } \\
\text { relativa }\end{array}$ & $\begin{array}{c}\text { A exatidão / pontualidade é } \\
\text { manifestada ao extremo }\end{array}$ \\
\hline As relações são mais intensas e \\
duráveis & $\begin{array}{c}\text { As relações são mais superficiais e } \\
\text { mais passageiras / transitórias }\end{array}$ \\
\hline
\end{tabular}

Fonte: Adaptado a partir de HALL e HALL, p. 49/50.

O quadro anterior não deve ser tomado literalmente. Serve, no entanto, para que mais adiante ilumine considerações referentes à base empírica deste estudo. Em seguida serão apresentados alguns elementos característicos das culturas brasileira e alemã.

4 Sobre esta questão ver HALL E HALL, 1990, PATEAU, 1994 e TREVISAN, 2001. 
O resgate histórico do processo de colonização é fundamental para a análise da cultura brasileira. Inserido no contexto de expansão do capitalismo mercantilista ${ }^{5}$ europeu dos séculos XV e XVI, este processo colocou em contato os três grupos étnicos que serviram de base para a formação do povo brasileiro: portugueses, indígenas e africanos ${ }^{6}$.

Mesmo evitando reducionismos economicistas, não se pode deixar de considerar que foram razões econômicas as que trouxeram os portugueses para o Brasil e, mais tarde, os fizeram tentar se utilizar do trabalho escravo dos povos indígenas primeiramente e, frente ao insucesso de tal empreitada, posteriormente buscar a solução do problema da mãode-obra na exploração nas costas africanas para o comércio de escravos (TREVISAN, 2001).

Uma vez em território brasileiro, e frente às condições impostas pela distância da metrópole, os brancos europeus, apesar de seu status e domínio de colonizador, "que por isso podiam impor-se aos indígenas e negros africanos - foram flexíveis em adaptar-se a costumes e práticas destes para garantir seu próprio empreendimento" (TREVISAN, 2001, p. 30).

A miscigenação em larga escala que ocorreu durante todo o processo de colonização pode ser interpretada como uma faceta de tal flexibilidade que, segundo os estudiosos da área, é responsável pela formação da matriz principal do povo brasileiro ${ }^{7}$.

5 No que tange às condições econômicas, é importante ressaltar que o Brasil sempre ocupou um papel de subordinação em relação às potencias econômicas estrangeiras, fossem elas Portugal, no período de colonização, ou Inglaterra e Estados Unidos no período de independência política. Este fato, unido a uma série de outros fatores sócio-históricos, deram origem a sérias disparidades e desigualdades sociais. Tais condições tiveram graves repercussões no que se refere à formação da identidade do povo brasileiro, sempre disposto a valorizar artigos e produtos culturais vindos de fora em detrimento de suas próprias produções. Sobre o tema ver PRADO JR, 1971.

6 Sobre a formação e o sentido do povo brasileiro ver RIBEIRO, 1995.

7 Apesar das contribuições destas matrizes citadas, bem como de outras que se integraram a elas mais tarde (europeus não ibéricos, asiáticos e árabes entre outros), há que se ressaltar o caráter único do povo brasileiro, que sendo muito mais que uma soma de elementos étnicos, constitui-se em um novo ser, uma nova etnia, cuja diversidade é sua principal marca (RIBEIRO, 1995). 
Contradizendo o mito da democracia racial - que vigora em vários estratos da sociedade brasileira - é importante ressaltar que este processo não se dá de forma harmônica, pois, principalmente em seu período inicial

a sociedade era, de fato, um mero conglomerado de gentes multiétnicas, oriundas da Europa, da África ou de nativos daqui mesmo, ativadas pela mais intensa mestiçagem, pelo genocídio mais brutal na dizimação dos povos tribais e pelo etnocídio radical na descaracterização cultural dos contingentes indígenas e africanos (RIBEIRO, 1995, p. 448).

A partir deste pano de fundo, forjou-se uma sociedade marcada por antagonismos e contradições, dentre as quais destaca-se a do senhor e do escravo, a qual - mesmo após o processo abolicionista - tem marcas profundas na identidade nacional.

Em meio a este contexto há que se ressaltar o caráter fundante desempenhado pela família, seja em seu papel econômico - na medida em que se constitui a unidade produtora em torno da qual se desenvolveu a economia brasileira durante boa parte da sua história - seja em seu papel de organizadora das relações sociais, já que em torno da mesma se estabeleceram os parâmetros de sociabilidade a partir de uma estrutura patriarcal. Esta define os papéis sociais desempenhados por homens e mulheres nesta mesma sociedade.

Aos homens coube, tradicionalmente, o papel de provedor - senhores dos destinos da família e de seus agregados. Às mulheres, os afazeres domésticos - sendo que também por força da tradição, ocupariam papel de subordinação em relação ao homem (CARVALHO, 1992). Deve-se ressaltar que embora os valores da família patriarcal sejam vigentes ainda hoje, em virtude de transformações econômicas, sociais e políticas seus pressupostos - também com relação a gênero - podem ser questionados e estão sujeitos a mudanças.

Este modelo das relações familiares pode ser estendido a outras esferas do agir inter-pessoal, tais como a política, a religiosa 
ou econômica. Logo, o patriarcalismo constitui-se também numa das bases de uma sociedade onde "os vínculos de parentesco, ou laços afetivos ou as relações de qualquer natureza com um senhor tornam-se suficientes para garantir privilégios numa sociedade hierarquizada" (TREVISAN, 2001, p. 32).

Tem-se então, como característica da cultura brasileira, o caráter singular e preponderante que as relações entre pessoas (protegidas pelas relações pessoais) têm sobre as relações entre indivíduos (sujeitos às leis). Isto porque, na busca por evitar conflitos, institui-se o estilo pessoal nas relações a fim de marcar posições hierárquicas que não se sustentariam numa estrutura social onde os indivíduos seriam considerados naturalmente iguais (DA MATTA, 1980).

Desta forma o Brasil se constitui numa sociedade híbrida não apenas do ponto de vista da miscigenação étnica, mas na própria cultura, visto que os brasileiros via de regra não gostam de reconhecer o conflito, mas utilizam recursos como o "você sabe com quem está falando?" para estabelecer as hierarquias e o poder, mantendo portanto, a desigualdade; utilizam o "jeitinho [brasileiro]" para contornar situações morosas e burocráticas visando obter uma solução pela via do favor e da simpatia (TREVISAN, 2001).

As características apontadas acima não esgotam o complexo universo da cultura brasileira, no entanto servem como base para uma discussão de seus desdobramentos na formação das identidades individuais. Com respeito ao gênero, ajudam a compreender as especificidades que marcam as relações entre homens e mulheres em diferentes dimensões da vida social, especialmente no mundo do trabalho e da tecnologia, objeto específico desta investigação.

8 A relação patriarcal não foi a única que se estabeleceu nesta nova formação social (ver CORREA, 1982), porém foi a formação dominante que constituiu a base para outras relações sociais que marcaram profundamente a sociedade brasileira.

9 Baseado em DA MATTA, 1980 e 1986. 
Com relação ao povo alemão, há que se iniciar apontando para 0 caráter milenar de sua cultura, cujas origens remontam aos primórdios da Idade Média, ainda sob o reinado do imperador Carlos Magno. Esse povo é fruto da síntese de várias etnias, embora não seja mais possível perceber diferenças entre elas ${ }^{10}$.

A criação de seu Estado Nação - na segunda metade do século XIX - constituiu-se em um marco para a história da Alemanha, não apenas em termos políticos, mas também econômicos e culturais. A partir de 1871 e das várias vitórias sobre seus rivais:

(...) a Alemanha, viu-se quase que automaticamente envolvida num rápido processo de recuperação do tempo perdido e na tentativa de ultrapassar as grandes potências européias mais antigas; sob a pressão dessa rivalidade, encontrou-se na voragem de um acelerado processo de modernização que imprimiu um impulso decisivo aos grupos especializados da economia, às classes médias industriais e comerciais e à força de trabalho industrial (ELIAS apud TREVISAN, 2001, p. 40).

Do período da unificação - década de 1870 - até a Primeira Guerra Mundial, pode-se afirmar que a cultura alemã, principalmente no que tange à formação de valores, passou por uma espécie de deslocamento: dos ideais aristocráticos da nobreza para praticidade utilitarista da burguesia - de uma conduta que tinha por base a honra para outra que se ancorava na virtude.

No período entre guerras foram gestadas as condições para 0 surgimento e ascensão do nazifascismo. Nas palavras de Elias:

A repugnância sentida por muitos alemães quando, após $o$ (...) desaparecimento [do Kaiser], se encontraram pela primeira vez diante da tarefa de decidir, sem o supremo

10 As informações sobre a cultura alemã apresentadas neste artigo foram obtidas através de consulta às seguintes obras: HALL e HALL, 1990, PATEAU, 1994 e TREVISAN, 2001. 
comandante-chefe, sem suas ordens vindas de cima, por quem deveriam ser governados, não foi fruto somente de que o horror suscitado pelos "pobres", os trabalhadores, também tinham agora o direito de participar no governo e de que, por conseguinte, homens de baixa categoria estavam exercendo funções governamentais. A reação desses alemães era, ao mesmo tempo, uma expressão do fato de que, de súbito uma figura central na cena social com quem a estrutura da personalidade deles, estava sintonizada já não estava mais ali. O seu lugar fora tomado por figuras que não correspondiam nem à estrutura da personalidade nem ao tipo de código de comportamento que eram os deles (ELIAS, apud TREVISAN, 2001, p. 42-43).

Muitos analistas explicam através deste contexto a ascensão de Hitler, do nazismo e o advento da Segunda Guerra. Toda esta conjuntura teria na sua origem "essa relativa dificuldade de conviver com conflitos parlamentares associada ao desejo de muitos alemães de um governante que centralizasse o poder, possuindo força e grandeza capaz de protegê-los de si mesmos e de seus inimigos" (TREVISAN, 2001, p. 43).

No entanto, tais sonhos e projetos se viram frustrados através dos eventos do final da Segunda Guerra: além da fragorosa derrota, viram seu território ser dividido em dois países, um deles - A Alemanha Oriental - sob regime socialista.

Já a Alemanha Ocidental passou por um rápido processo de reconstrução onde, no espaço de apenas algumas décadas, teve sua economia alçada ao grupo dos países mais ricos do mundo. Com a derrocada do socialismo real no leste europeu foi a protagonista do processo de reunificação da atual Alemanha.

Esta conjuntura histórica conturbada repercutiu profundamente sobre a cultura alemã. Um dos efeitos marcantes foi a ascensão do catolicismo que se traduziu inclusive como proposta política. A democracia cristã alemã apontava para a efetivação do modelo liberal. 
Destaque-se que neste momento a juventude alemã assume uma postura de negação dos valores das gerações anteriores. Neles os horrores do período nazista forjaram "um ethos muito acentuado de resistência à desigualdade, à opressão, à exploração e à guerra, e a favor de um novo tipo de decência entre os seres humanos" (ELIAS apud TREVISAN, 2001, p. 45).

Os antigos valores foram associados ao contexto nazista e por muitos são vistos como ultrapassados. No entanto, segundo os estudiosos da cultura alemã, tal fenômeno gerou uma certa carência na formação de sua identidade.

Faz-se necessário então, levantar tópicos específicos sobre alguns valores da cultura alemã: por exemplo, o indivíduo deve assumir suas responsabilidades perante o grupo. Assim "o homem deve ter a coragem de ser individual, de não recuar diante de suas responsabilidades e diante das decisões a tomar" (PATEAU, apud TREVISAN, p. 46).

Em suas práticas cotidianas, os alemães tendem a respeitar acordos estabelecidos. Seu estilo de comunicação é explícito e direto e a prática da discussão é amplamente utilizada para a construção de consensos.

Metódicos em suas tarefas, dedicam grandes parcelas de tempo na execução das mesmas, o que às vezes pode ser tomado como falta de criatividade. Exatidão, pontualidade e rigor são consideradas virtudes essenciais, principalmente no ambiente profissional, onde as relações devem ser impessoais e distantes. A privacidade é um valor extremamente importante. Seja na família ou nas amizades, o espaço pessoal sempre é respeitado. Os pesquisadores apontam que, em virtude de uma forte necessidade de adequação, os parâmetros para a ação estão centrados nas regras e não nas relações interpessoais (TREVISAN, 2001).

Conforme já foi mencionado, não se pretendeu esgotar através do levantamento de tais características o riquíssimo repertório das duas culturas abordadas. O objetivo foi apenas apresentar a moldura onde está inserida a base empírica deste estudo. A seguir passar-seá às considerações gerais sobre as pesquisas realizadas no Brasil e Alemanha, para depois fazermos comparações entre as representações de gênero de estudantes alemães e brasileiros. 


\section{CONSIDERAÇÕES GERAIS SOBRE AS PESQUISAS ${ }^{11}$}

Ambas as pesquisas partiram da idéia de que o número de mulheres nos cursos da área técnica é pequeno quando comparado ao número de homens. Entre as muitas indagações que estavam na origem deste estudo, as seguintes podem ser destacadas: Como se estabelecem as relações de gênero entre os estudantes e as estudantes dos cursos de tecnologia? Há diferenças de gênero em cursos tecnológicos de diferentes países?

A partir destas indagações, definiu-se a execução de pesquisa qualitativa, com os seguintes objetivos: 1. conhecer as concepções e representações de gênero entre estudantes (homens e mulheres) de cursos de tecnologia; 2. comparar os resultados das investigações realizadas no Brasil e Alemanha.

Os métodos de investigação foram os mesmos nos dois países, a etnometodologia, que consistiu em entrevistas abertas em grupo com pessoas que viveram experiências comuns. Participaram da pesquisa brasileira alunos do sétimo período dos cursos de Tecnologia em Móveis e Tecnologia em Artes Gráficas da Universidade Tecnológica Federal do Paraná (UTFPR) e da pesquisa alemã os alunos do curso de Mídias Digitais da Fchhochschule - Furtwangen (FHF).

Os alunos participantes desta pesquisa podem ser caracterizados, como jovens pertencentes à camada social média, solteiros em sua maioria e com alguma experiência profissional - ainda que somente em estágio ${ }^{12}$.

Este trabalho se orientou através de duas dimensões fundamentais: uma da cultura e outra de gênero como mostra o modelo a seguir:

11 Os textos de CARVALHO, M.G et al e SELKE, S., que estão nesta mesma publicação, trazem maiores detalhes sobre a contextualização da investigação, seus suportes teóricos, a metodologia detalhada da pesquisa e os resultados em sua íntegra. Como o presente artigo tem como objetivo fazer uma comparação entre seus resultados, julgou-se desnecessário trazer novamente os detalhes já apresentados.

12 Maiores informações sobre os participantes da pesquisa no Brasil podem ser obtidas no quadro de caracterização no texto de CARVALHO et al, nesta edição. 


\section{BRASIL}

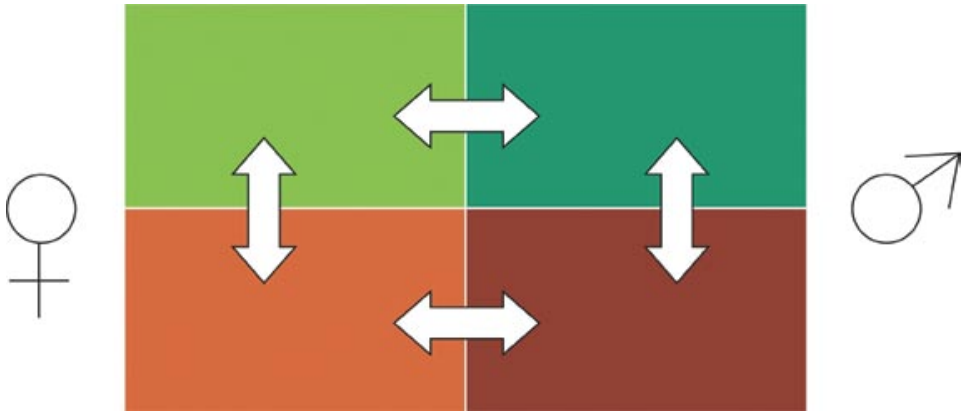

ALEMANHA

A dimensão cultural da pesquisa pode ser observada pelas setas verticais. O campo superior representa o Brasil e o inferior a Alemanha. Já as relações de gênero aparecem representadas pelas setas horizontais, sendo o campo da esquerda o lado feminino e o campo da direita o lado masculino. A comparação foi realizada em quatro níveis:

- entre mulheres brasileiras e mulheres alemãs,

- entre homens brasileiros e homens alemães,

- entre mulheres brasileiras e homens brasileiros e,

- entre mulheres alemãs e homens alemães.

O projeto teve como finalidade chegar a estas comparações através da análise das informações obtidas nas entrevistas com os alunos e alunas, das quais foram consideradas as diferenças de atitudes, as diferenças culturais, bem como os diversos valores e normas que permeiam a sociedade em que estão inseridos.

\section{ANÁLISE COMPARATIVA DAS REPRESENTAÇÕES DE GÊNERO ENTRE ESTUDANTES BRASILEIROS E ALEMÃES ${ }^{13}$}

A abordagem intercultural trouxe uma riqueza para a temática sobre a construção do gênero no meio tecnológico e permitiu comparar questões

13 Uma versão preliminar das análises que são aqui apresentadas podem ser encontradas em Carvalho (2006). 
pertinentes à diversidade cultural e as transformações e permanências nas identidades de gênero que estão ocorrendo.

Sabe-se que o processo de socialização diferenciado para meninos e meninas resulta em padrões de gênero dicotomizados que separa a vida social em duas esferas com características opostas. Apesar da realidade social ser muito mais rica e múltipla do que apenas modelos binários, a construção do masculino e feminino tem seguido esta dicotomia, o que traz problemas de ordem teórica para a adequada interpretação sobre as relações de gênero no mundo atual que é cada vez mais plural e multifacetado ${ }^{14}$. No entanto, esta dicotomia aparece na realidade social de maneira enfática, especialmente em se tratando do universo tecnológico. Estas influências relacionadas com a socialização são altamente funcionais como resultado de orientação, porque elas ordenam o mundo da vida. Os resultados desta pesquisa assim o confirmam em que pesem as diferenças culturais entre Brasil e Alemanha.

Uma afirmação comum entre os/as estudantes logo no início das entrevistas foi de que não percebiam discriminação ou relações de poder entre as moças e rapazes do Curso. Disseram, também, que não havia diferenças de tratamento entre eles e elas, portanto no curso e na profissão “era tudo a mesma coisa”. Apesar das evidências de diferenças de gênero reveladas pela pesquisa, nas representações dos alunos brasileiros e alemães essas diferenças não foram explicitadas conscientemente. Porém, na seqüência das entrevistas, as diferenças afloraram.

\section{HABILIDADE TÉCNICA X DEPENDÊNCIA}

O papel da família assim como as relações e experiências vividas neste âmbito foram fundamentais para a formação dos padrões de gênero entre as pessoas do universo investigado. Na Alemanha, tanto as moças quanto

14 Hoje em dia não é mais possível pensarmos em apenas um modelo para homens e mulheres, constituídos como realidades opostas. Os grupos existentes e as situações vividas geram uma pluralidade de papéis para eles e elas. Compreender as relações de gênero leva a considerações sobre esta multiplicidade e também sobre as relações de poder que perpassam o universo de interações entre homens e mulheres, homens e homens, além de mulheres e mulheres (SCOTT,1995). 
os rapazes admitem que desde tenra idade são direcionados diferentemente para interesses que os aproximam (no caso dos rapazes) ou afastam (no caso das moças) das habilidades técnicas.

De uma forma bem mais nítida que as mulheres, os homens podem procurar o motivo da sua aptidão técnica nas repetidas atividades lúdicas relacionadas com a mesma na infância e juventude. A ocupação nesta área fica relacionada com empolgação, e boas experiências com brinquedos são facilitadas aos meninos através de uma clara divisão dos papéis.

Como observação mais marcante para muitos participantes vale, neste caso, o papel de ídolo do pai, que representa soberania no manuseio da tecnologia (mesmo que domiciliar) e representa conseqüentemente um modelo para o domínio do próprio mundo frágil. A afinidade e o manuseio de artefatos de ponta, porém, pode também ser entendida como estratégia de compensação de conflitos internos e interpessoais. O controle da técnica muitas vezes se transforma em sinônimo de autocontrole.

Neste contexto, as meninas não se orientam da mesma forma. Aprendem com as mães estratégias duplas para a construção de identidades, que poderão a vir a ser mais ou menos bem sucedidas, visto que a cultura alemã é inflexível no que diz respeito ao papel de mãe.

Esta ambivalência (necessidade de conciliar sucesso profissional e tarefas domésticas pertinentes ao seu gênero), que aparece de forma recorrente entre as entrevistadas alemãs, não pode ser percebida entre as brasileiras. Tal silêncio pode ser interpretado de muitas formas, inclusive pela estrutura cultural brasileira que permite às mulheres se valerem do auxilio de babás e empregadas domésticas no exercício das tarefas do lar e no cuidado com os filhos (o que não é possível no caso das alemãs).

Assim, são transmitidos diversos princípios básicos de uma consciência de gênero relativamente complexa, em especial o fato de que podem existir competências técnicas nas mulheres, porém, estas não podem ser demonstradas ou vividas ou o podem somente dentro de um contexto limitado. No caso das mulheres, interesse explícito nesta área somente acontece quando se trata de uma exceção.

Não houve na pesquisa brasileira, falas que permitissem análises que ligassem processo de socialização e afinidades com a técnica. No entanto, 
esta relação, no Brasil, poderia ser inferida quando algumas informantes afirmam que os meninos teriam uma tendência "natural" com relação às máquinas. Isto poderia ser fruto do processo de socialização. O que aparece nas falas dos estudantes brasileiros, na maior parte das vezes indiretamente, é o seu papel forte na internalização de estereótipos de gênero de origem biológica. Assim, constroem-se identidades já orientadas para a ocupação de espaços públicos e privados, maior uso ou não da objetividade ou subjetividade, etc. de acordo com o sexo. Isto contribui para a manutenção da subordinação feminina.

O desenvolvimento do interesse técnico de forma desigual entre meninos e meninas tem sua continuidade nas escolas alemãs na medida em que as mesmas reforçam ainda mais os interesses masculinos para lidar com equipamentos e conhecimentos técnicos e os interesses femininos para apenas usarem esses equipamentos sem necessariamente compreenderem o seu funcionamento, nem desenvolverem interesse para esta compreensão.

No processo de socialização emerge a afinidade técnica dos homens nas atividades lúdicas, permitindo aos mesmos as experiências agradáveis, porque esse interesse (re-) vivido leva sucessivamente à formação de competências, que na sua totalidade se fundem em um modelo da assimilação da realidade e domínio do mundo. Este processo torna-se para os homens uma atividade simbólica, pela qual os mesmos se reconhecem.

Tais formas de socialização, primária e interfamiliar, continuam na escola ou durante a formação. Porém, aqui fica visível um deslocamento de ênfase: primeiro se exige das meninas menos interesse, entendimento e, conseqüentemente, empenho operacional nas matérias técnicas. Segundo, se espera que as meninas não precisem mostrar empenho verdadeiro, para ter sucesso na escola ${ }^{15}$. Permite-se a elas o conhecimento aprendido, porém não o entendimento básico. Esta compreensão androcêntrica aparece de forma variada. As experiências educativas em que esta diferenciação é vivida e percebida, de forma aberta e permanente, pelos outros estudantes

15 Louro corrobora esta idéia quando analisa as atitudes dos/as professores/as em sala de aula que incentivam os meninos a um comportamento criativo e às atividades técnicas e cobram das meninas um comportamento disciplinado e passivo, deixando-as, algumas vezes, sem a oportunidade de desenvolver a criatividade naquelas áreas (LOURO, 2001). 
colocam a pedra fundamental para um Manual de como ser dependente, de onde é provável que poucas meninas consigam fugir. $\mathrm{O}$ seguinte exemplo ilustra as dificuldades que as meninas têm que enfrentar em um ambiente de ensino dominado pelos homens. Uma participante lembra, como ela teve que enfrentar o professor: "eu era a única menina no curso de informática e quando eu pedi uma informação a ele, ele simplesmente tirou o teclado da minha mão e eu falei para ele que eu mesma queria fazer aquilo".

Estas diferenças os/as acompanham pela vida estudantil e quando vão conviver em um mesmo Curso da área tecnológica percebem que os rapazes são mais interessados em desmontar e conhecer os aparelhos e computadores (no caso específico desta pesquisa) enquanto as moças não têm este interesse, mas apenas querem conhecer sua aplicabilidade para poderem deles usufruir. Por exemplo, no caso da Alemanha, eles estão mais ligados em programação e projetos, enquanto elas estão mais interessadas na criação. Eles dizem que elas não estão interessadas no funcionamento dos computadores e elas admitem que os rapazes são melhores técnicos do que elas. Por outro lado, os rapazes dizem que as moças são bem melhores no relacionamento com as pessoas.

Âs mulheres é transmitida uma consciência de gênero complexa, o que se demonstra, como já referido, pela maneira, mais ou menos bem sucedida de viver duplas estratégias na construção de modelos de identidade. Estas incluem a convivência ambivalente com a própria competência, que quando existe, pode ser vivida somente de forma limitada. A falta de clareza sobre critérios de êxito para as mulheres e a assimilação de um entendimento básico androcêntrico, implicam em atribuições que exigem menos competência às meninas. Como elas têm menos chances de comprovar o contrário, são obrigadas à estratégia do silêncio. Aqui se encontra um elemento básico para induzi-las a serem dependentes, formando um contraste forte em relação às experiências prematuras dos meninos.

\section{A TRANSVERSALIDADE DO GÊNERO NO CURSO E NA PROFISSÃO}

De acordo com Scott, 1995, gênero é uma categoria de análise, através da qual se pode interpretar a vida social e suas diferentes dimensões e manifestações. A sociedade está perpassada pelo gênero e, como tal, 
não poderia deixar de ser também com as relações entre estudantes nem com as que se estabelecem no mundo do trabalho. Neste caso, costuma-se considerar gênero como um tema transversal das relações sociais.

No Brasil, os depoimentos das mulheres revelaram que elas consideram os homens mais firmes e discretos, observam ainda que eles simplificam as coisas o que agrega valor ao seu trabalho. Eles vão estudar cursos como engenharia porque se dão melhor em áreas técnicas e das ciências exatas. Interessam-se mais para trabalhar com computadores e por programação.

Elas disseram que na vida profissional os homens destacamse mais do que as mulheres. $\mathrm{Na}$ área de design, por exemplo, na qual há um número razoável de mulheres, os homens são os profissionais mais reconhecidos. Segundo elas, os homens são mais firmes em suas posições profissionais, são mais discretos, têm idéias "geniais" e eles não complicam os trabalhos, apesar de serem também mais desorganizados e nem sempre terem muito capricho.

A força física foi uma característica masculina bastante citada pelos rapazes (e moças) para apontar as diferenças entre homens e mulheres ${ }^{16}$. Outras diferenças entre moças e rapazes citadas por eles/elas: os homens têm mais facilidade para lidar com as ciências exatas, com trabalho mecânico, são mais agressivos no trabalho, como por exemplo, na apresentação de um projeto. Por outro lado, as mulheres são mais organizadas. De acordo com a opinião deles, as mulheres têm mais facilidade e mais tato para lidar com o público e trabalham melhor com decoração.

Uma limitação das mulheres de acordo com a percepção masculina foi com relação a conhecimentos técnicos "grande parte das mulheres não gostam de coisas muito minuciosas que têm muitos comandos... mulher vai achar que motor tem válvula de televisão”. Eles disseram que lidam com equipamentos técnicos, porém se ocorrer algum problema não tentam resolver e geralmente recorrem a seus colegas masculinos para pedir ajuda.

16 A questão da força física está presente nos depoimentos dos/as brasileiros/as e não aparece entre os/as alemães/ãs por uma especificidade dos cursos pesquisados. O Curso de Mídias Digitais não exige praticamente nenhuma atividade onde seja necessária a força física, enquanto que no Curso de Tecnologia em Móveis, muitas vezes esta característica é necessária. 
Segundo eles, é muito difícil encontrar uma mulher que tome a iniciativa de solucionar sozinha este tipo de problema.

Esta percepção coincide com os resultados da pesquisa entre os jovens alemães que se referiram ao já citado Manual de como ser dependente que é construído no processo de socialização das meninas e de onde somente poucas delas conseguem fugir. E justamente porque elas não dispõem destes "pré-requisitos" são excluídas de cursos para os quais futuramente se exigirá conhecimentos mais profundos. Estes conhecimentos são presumidos nos meninos com uma certa evidência. As meninas logo cedo têm a experiência de que, no que se refere às matérias técnicas, terão dificuldades para assimilar e apreender esses conteúdos a partir da base ${ }^{17}$. Elas terão que desenvolvê-los e construí-los através da prática acadêmica.

No Brasil, uma situação análoga foi reconhecida pelas próprias meninas. As entrevistas revelaram a idéia de que as mulheres são observadas com desconfiança no que se refere ao domínio dos conteúdos específicos de sua área de atuação. No entanto, a análise das entrevistas não permite afirmar que enfrentarão as mesmas dificuldades apontadas pelas alemãs.

Os rapazes da UTFPR acreditam que o homem, pelo menos neste campo de atuação (Curso de Artes Gráficas e Desenho de Móveis), tem que ter uma interação positiva com a tecnologia, creditando o sucesso na profissão à busca e ao domínio de novos conhecimentos. Isto porque consideram moderno e inovador este ramo do mercado não estando, portanto ligado a padrões tradicionais estabelecidos. Como consideram que todas estas características são masculinas, é recorrente a idéia de que os homens têm um melhor desempenho profissional que as mulheres.

A maneira de ver o mundo é importante para melhor entender as diferenças entre os gêneros. Uma participante da pesquisa de FHF descreveu que no trabalho ela olha mais os contextos e também as pessoas com as quais lida. Não vê apenas a tarefa que deve ser cumprida, mas também o seu conjunto "com o que tem a ver a tarefa".

$17 \mathrm{Na}$ Alemanha as mulheres encaram o curso como uma possibilidade de aprender. No Brasil isso não aparece. 
Os jovens da UTFPR apontam que homens e mulheres possuem diferentes formas de reagir ao stress no ambiente de trabalho, marcadas pelo gênero: as mulheres exprimindo através do choro, os homens através do lúdico.Disseram que as meninas são muito detalhistas, "gostam de complicar as coisas...". Para eles o ambiente de trabalho em que há muitas mulheres é mais tenso porque elas não conseguem separar questões profissionais de questões pessoais: "a mulher leva tudo pro lado sentimental, qualquer coisinha, se você falar atravessado, ela vai pro banheiro chorar, vai pro canto, tem enxaqueca...”. De acordo com as opiniões deles, "para os homens essas questões são resolvidas de forma mais simples: ficam putos, vão pra um bar, tomam uma cerveja e no dia seguinte está tudo bem".

Tem-se aqui uma semelhança entre brasileiros e alemães: para ambos o espaço masculino é fechado às mulheres ou, no mínimo, procurase mostrar a superioridade masculina. No Brasil aparece nas entrevistas a idéia de que homens se sentem pouco à vontade em ambientes femininos. Por diferentes motivos a recíproca também é verdadeira.

As mulheres são vistas pelos rapazes em sua maioria como emotivas, sentimentais, sensíveis, delicadas, cuidadosas, mais subjetivas do que os homens. Estas características acarretam algumas conseqüências nas relações de trabalho que podem, por um lado, favorecer o desempenho das mulheres em algumas atividades e, por outro, prejudicar. Por exemplo, a sua sensibilidade e delicadeza são importantes no trabalho com o público, onde elas são mais eficientes. Disseram que esta capacidade de relacionamento faz com que as mulheres consigam galgar posições, ter mais carisma, para outros,

(...) no setor de criação, de concepção de arte, de design a mulher leva teoricamente uma certa vantagem até por questôes psicológicas,... é tão da mulher ser lapidada pra ser mais aprazível... ela tem mais percepção pra coisinhas que estão acontecendo no trabalho... ela pode tomar isso como um novo ramo, um novo caminho para criação (...) 
Outras qualidades apontadas como femininas e que favorecem o desempenho das mulheres no trabalho foram a organização e uma maior atenção a detalhes e a cores. São eficientes em trabalhos como controle de qualidade, de acabamento, por exemplo, e também no setor financeiro. De acordo com os estudantes brasileiros, elas têm também mais facilidade para trabalhar em redação e mídia.

Os jovens alemães reconhecem que também existem homens, "que possuem algo dos dois lados”. Há que se lembrar que, no caso alemão, esta expressão não traz em si nenhuma referência a comportamentos homossexuais ou a discriminação de gênero. Já no Brasil, tais preconceitos para com aqueles que optam pelos cursos de Desenho de Móveis e Artes Gráficas são recorrentes (note-se que, por serem consideradas "femininas", estas áreas são alvo de preconceito dentro mesmo da UTFPR). Talvez, por isso, como mecanismo de defesa, os meninos afirmem a modernidade destes campos, o que levaria à quebra dos padrões tradicionais. No entanto, eles deixaram transparecer uma certa consciência de que serão considerados homossexuais devido à profissão que escolheram. Na Alemanha, as mulheres que optam pelos cursos da área tecnológica agem de acordo com padrões de comportamento tipicamente masculinos para poderem competir com seus colegas. Neste caso, são elas que terão de arcar com este tipo de preconceito de gênero.

Porém a existência de duas esferas de pensar basicamente diferentes e quase completamente incompatíveis não é questionada. Na representação dos/as estudantes brasileiros e alemães o modelo de duas culturas, baseado na divisão em uma esfera emocional e outra esfera racional, fica ratificado tanto pelos homens como pelas mulheres.

As alunas da FHF acreditam que os homens possuem uma tendência "natural" ao pensamento lógico. A eles é atribuída uma certa facilidade para pensar em estruturas, enquanto as mulheres preferem se concentrar em processos. Uma das participantes também vê nesta diferença o motivo para as dificuldades na matéria "Programar", que é elementar para os cursos na área de Mídias Digitais. "Para tal coisa não tenho a visão lógica, para a programação". 
As chamadas estruturas de pensamento não são a consequiência necessária de interesses técnicos marcados diferentemente para moças e rapazes, contudo são a sua base. Como critério para diferenciar as subjetividades dos estudantes femininos e masculinos na área de Mídias Digitais pode-se apontar um certo desinteresse básico por parte das mulheres.

Os meninos entretanto ocupam uma posição de descobridor, porque eles reconhecem as oportunidades de aproveitamento e aplicação dos computadores, enquanto as mulheres seriam cegas para tal fato, pois "o interesse é estimulado mais cedo (...), se começa com On-line Games, sei lá. E depois se pode, (...) que bacana, posso escrever um Script, então posso modificar no arquivo alguma coisa. Uma mulher nunca tem uma idéia dessas, de que isto é possível”.

A fala acima demonstra a desconfiança dos rapazes em relação à competência das moças. Isto também fica explícito quando atuam em grupos de trabalhos mistos, onde a idéia é de exploração feminina do maior conhecimento masculino na área técnica. No Brasil, ao contrário, a complementaridade parece ser a tônica nestas situações ${ }^{18}$.

Pela visão dos rapazes alemães, seu interesse por computadores é quase automático. Isto se acentua até atingir um posicionamento fatalista, e evidencia ainda mais a seletividade da própria percepção: "Não se consegue fugir daquilo". O descobrimento e a ampliação do próprio interesse técnico acontece através de brincadeiras, e em um determinado ponto de transição, o acesso lúdico e infantil se transforma em um interesse sério e adulto: "A vontade de brincar acabou e o interesse na tecnologia aumentou mais".

Tem-se aqui uma diferença com relação ao caso brasileiro: para estes estudantes o uso da tecnologia está ligado à expressão artística, o que representaria uma ruptura em relação a modelos tradicionais de comportamento, enquanto que, para os estudantes alemães, optar pelo curso de Mídias Digitais representa continuidade e reprodução de papéis e modelos tradicionalmente estabelecidos.

No entanto, a referida "propensão natural" não isenta os entrevistados de ambos os países de certos preconceitos de gênero. Um estudante

18 Note-se que os alunos alemães estão se referindo a grupos de estudo, enquanto que os brasileiros a equipes de trabalho na instituição e nos estágios. 
brasileiro revelou explicitamente que as mulheres não interagem bem com aparelhos e artefatos tecnológicos, sendo este um dos fatores limitantes para sua atuação no mercado de trabalho. "Quem que vai lá abrir a máquina, mexer nas placas pra ver como é que tá, os contatos da placa, desmontar e montar de novo? É difícil as mulheres que fazem isso. Eu particularmente nunca vi nenhuma”. Apontam, no entanto, que existem exceções, já que na maior parte das vezes, na área de artes gráficas, restaria às mulheres o trabalho com redação e atendimento ao público.

No Curso de Tecnologia em Móveis, o fator limitante apontado para as moças nas seleções de estágio e nas poucas experiências no mercado de trabalho foi a já citada falta de força física, quando argumentos científicos foram acionados em diversas situações: "Está cientificamente comprovado que a mulher é fisicamente mais fraca que os homens". Esta argumentação foi utilizada tanto pelas moças como pelos rapazes, apesar de algumas apontarem para o fato de que nem sempre a força física é necessária e quando o é, elas realmente "carregam móveis pesados pra baixo e pra cima”. Muitas vezes os próprios professores também duvidam da capacidade delas para exercerem esse trabalho ${ }^{19}$.

A insegurança profissional foi também apontada pelos rapazes como uma característica feminina que dificulta sua afirmação na profissão. Trouxeram exemplos de colegas de curso que não se impõem na defesa de seus projetos e opiniões, não defendem suas idéias com a mesma firmeza e agressividade que os colegas rapazes e não ousam criar nada além do que os professores orientam “(...) tudo quadradinho, bonitinho, bem resolvido, mas é aquilo. Não vai ter diferença... são mais tranqüilas, mais serenas... é um trabalho assim, assim,... sem muita gana”. Eles apontaram suas colegas de curso como mais disciplinadas e estudiosas do que eles "são bem mais dedicadas,... são mais cdf [exageradamente estudiosas] se preocupam com mais antecedência com os trabalhos... a gente faz mais em cima

19 Tais argumentos, que apelam para a força física como fator limitante para a atuação da mulher no mercado de trabalho, não levam em consideração que, muitas das tarefas ditas femininas, exigem uma considerável força física, como por exemplo, carregar crianças pesadas no braço durante longos períodos de tempo e longas distâncias.... 
da hora (...)”.Na Alemanha, isto também seria verdade e poderia ser explicado pelo grau de resistência que as mulheres têm de enfrentar nos cursos da área tecnológica.

Constata-se que existe uma tendência das mulheres alemãs em subestimar a elas próprias e a outras mulheres, em relação às suas competências técnicas, enquanto os homens se superestimam. "Existem muitas que acham que não são tão boas assim e os meninos imaginam que são mega-bons”. A percepção da competência das mulheres pelos homens não está baseada de forma alguma em capacidades reais, mas sim em falsificações, clichês e preconceitos.

A competência ou é negada às mulheres ou elas são submetidas a uma prova minuciosa. Nos homens, a competência é considerada simples e automaticamente um pré-requisito. Tanto no Brasil como na Alemanha, aos homens são atribuídas capacidades de autodeterminação e solução objetiva e criativa de problemas, mesmo que os alemães estejam mais ligados à programação. No Brasil, as mulheres seriam responsáveis por soluções menos concretas, teóricas e óbvias ${ }^{20}$. No caso alemão, são inclusive mais práticas e criativas, gerando suspeitas nos homens. Tal desconfiança não foi detectada na pesquisa brasileira.

As estudantes alemãs têm a impressão de ter que se afirmar não somente perante os seus colegas, mas também perante os seus professores. Isto não é apenas uma observação marginal, mas é fortemente percebido pelas estudantes: "Deve-se mostrar talento ou dedicação para também ter, digamos, o direito de poder estar aqui". Independente de desempenhos concretos, as mulheres no início dos estudos devem se submeter a um ritual de apreciação, cujas regras obedecem à tradição de campos técnicos patriarcais. As estudantes brasileiras sentem a necessidade de se autoafirmar perante a UTFPR, uma instituição marcadamente masculina.

As mulheres vivem então o seu gênero de forma mais marcante que os homens, o que não é fruto de uma maior consciência do mesmo, mas simplesmente por terem mais oportunidades, mesmo que involuntárias,

20 Note-se que a não obviedade pode ser sinônimo de criatividade, o que parece que as mulheres não percebem. 
para isto. Isto não ocorre no caso brasileiro, embora apareça a idéia de que as mulheres devem se esforçar para estarem num espaço reconhecido como masculino.

Mesmo que as mulheres considerem a sua matriz de gênero como extremamente inadequada e inaceitável, elas tentam, no entanto, cumprir as exigências impostas ao seu papel. A absorção destes comportamentos deve ser realizada na forma de submissão a modelos de ação que são masculinos. Aqui se tem a mais importante experiência específica do gênero em relação aos estudos: as mulheres assumem inconscientemente exemplos de interpretação e critérios de relevância masculinos. "As mulheres, na verdade, não querem se 'adaptar'. Percebem, porém, que assumem traços masculinos".

Há, contudo exceções à regra, ou seja, homens que se interessam pela criação e mulheres que se interessam por programação. Segundo os alemães, o primeiro caso não é problemático porque é considerado uma competência complementar. O segundo caso é mais complexo. Quando mulheres "penetram” nos domínios masculinos e aprendem uma "profissão masculina”, tal fato ainda hoje provoca irritações. Não se fala abertamente sobre isto, mas elas são manifestadas em comentários sutis. Competências de mulheres que são perceptíveis explicitamente são imediatamente limitadas.

O método utilizado é a atribuição da pluralidade da competência e do seu deslocamento. Sem dúvida, a competência técnica é reconhecida, quando, por exemplo, uma mulher é encarregada da regência de um curso. Simultaneamente se supõe, que mulheres também utilizam a sua competência "natural" feminina = social, apresentando ao mesmo tempo uma "tarefa de educação". Assim se efetua um nivelamento, que tem como conseqüência 0 fato de que as mulheres, ao todo, parecem ser menos competentes.

No caso brasileiro, a discriminação para com a mulher surgiu com relação à preferência pelos rapazes para estágio ou colocação no mercado de trabalho. Vários casos foram citados por eles e por elas de que anúncios solicitando estágios não especificavam o sexo, porém no momento da seleção dos candidatos, mesmo quando a moça tinha melhor currículo ou competência, quem conseguia a contratação era sempre o rapaz. Os próprios 
rapazes reconheceram que para a mulher "se dar bem profissionalmente ela tem que ser muito mais competente do que os homens".

Segundo eles, as mulheres estão hoje conquistando muitos espaços no mercado de trabalho, mas esta conquista ainda é muito mais difícil para elas do que para os homens "ela briga duas vezes pra chegar e se impor. A imposição do homem é muito mais simples".

Há uma consciência entre os rapazes de que a sociedade está passando por um processo de transição, saindo de uma conjuntura em que as mulheres viviam em situações de submissão, onde os homens tinham muitos direitos que não eram estendidos a elas. Esta influência histórica ainda está presente entre ambos os sexos, como aponta um estudante brasileiro que afirma “(...) o sentimento [ de superioridade masculina] ainda está embutido na sociedade (...) tanto dos homens quanto das mulheres (...) existe muita mulher machista (...)”.

A fala anterior parece demonstrar que, se por um lado, os estudantes alemães parecem ter um maior sentido para suas experiências de socialização na formação de suas capacidades específicas, por outro, os brasileiros parecem reconhecer melhor o contexto histórico onde suas aptidões profissionais estão sendo formadas, são capazes de apontar tendências a transformações no mercado (que parecem ser pensadas como positivas).

De qualquer forma, as entrevistadas admitem a possibilidade de, com o tempo, as mulheres alcançarem reconhecimento nos ambientes masculinos. A conquista do espaço se daria, segundo elas, pela demonstração de sua competência ou pelo uso da diferença como estratégia de aproximação, onde as características femininas cativariam a afetividade masculina “... eles vão conhecendo, vão vendo como é o teu trabalho, aí começam a respeitar você, não só como profissional, mas também como pessoa; daí você conquistou o teu espaço, entendeu?".

Esta alegação não significa que tenha havido alguma mudança nas relações de dominação de gênero. $\mathrm{O}$ que houve foi uma adaptação a uma situação igualmente repressiva, como na Alemanha. A diferença é que lá as estudantes adotam o comportamento masculino para imporem a sua competência, enquanto que aqui, algumas recorrem às suas qualidades femininas, como por exemplo "sedução", para conquistarem seu espaço 
profissional. Por outro lado, houve também relatos de brasileiras que apontaram para o temor de uma certa "masculinização", na medida em que o desempenho de determinadas atividades que exigem força física colocaria em xeque sua feminilidade. Vê-se assim que há situações que ainda sofrem pressões dos estereótipos tradicionais.

\section{O HOMEM PROVEDOR: SEMELHANÇAS E DIFERENÇAS DE GÊNERO NOS DOIS PAÍSES PESQUISADOS}

Com relação ao papel masculino na sociedade, os homens alemães e brasileiros concordam com o fato de que é responsabilidade masculina o trabalho e o sustento da família. Esta representação foi expressa por eles de maneira diferente, porém este é um papel que, sem dúvida alguma, faz parte da construção da identidade masculina em ambos os países.

Entre os rapazes alemães a argumentação gira em torno do dogma da obrigação para a responsabilidade. Porque eles se vêem no "papel do provedor", eles se sentem em desvantagem perante as mulheres nas suas possibilidades de escolha. Um típico comentário é o seguinte: "Aqui nós temos outra vez outras obrigações. Nós temos que representar o papel daquele que sustenta. Por este motivo nós temos que fazer as coisas”. Este modo de pensar traz conseqüências para o relacionamento entre homens e mulheres. Isto pode ser representado pela seguinte metáfora extraída da discussão de um dos grupos de estudantes masculinos que estavam por concluir os seus estudos:

(...) este 'tem que' aparece muitas vezes. 'Tem que' significa uma obrigação. Vocês não querem, vocês devem. Então, eu também devo. Ou seja, então de fora vêm uma pressão para cima de nós, ou seja, emprego, carreira, qualquer outra coisa, isto sempre aparece, este tem que, que de fora vem uma certa pressão, eu tenho que fazer aquilo agora, para que eu o consiga de alguma forma. [...] Como homem você tem um motivo de dizer, 'ok, eu tenho que acelerar. Eu tenho que conseguir alguma coisa'. Ou eu preciso me erguer primeiro e depois, este tem que consta na frase de todos aqui. Por este 
motivo, provavelmente já respondemos. Esta obrigação que vem de fora. Você é um homem. Você tem que fazer. Então, refletir conscientemente sobre isto, provavelmente ninguém ainda fez. Nós sempre o fizemos, porque somos homem.

Esta “obrigação” foi apresentada como uma carga pesada através da qual eles devem direcionar as suas vidas, não conseguindo compatibilizar tarefas profissionais com tarefas familiares. Por esta razão a maioria deles não tem planos que incluam uma união estável. Observa-se neste depoimento a rigidez apresentada como característica da maneira de ser dos almeães ${ }^{21}$.

Ao contrário dos rapazes, as mulheres alemãs buscam exemplos positivos em sua própria rede social que demonstrem ser possível conciliar evolução profissional com a formação de uma família. Assim, permanecer no curso e seguir carreira tecnológica, na Alemanha, se subordinam às condições inerentes ao universo feminino. Tome-se, por exemplo, o caso da gravidez. Quando a mesma ocorre, as mulheres dificilmente poderão permanecer em suas atividades profissionais (por um período que pode chegar a dois anos), ficando sua atividade profissional em segundo plano. Note-se que no Brasil o assunto sequer foi mencionado.

Os homens não conseguem adicionar a educação de filhos com 0 trabalho, "assim não se consegue trabalhar direito, ou sofre o emprego ou os filhos”. Percebe-se aqui a dificuldade de conciliar várias atividades ao mesmo tempo, que, de acordo com a literatura consultada, é própria de culturas monocrônicas $^{22}$.

Os rapazes alemães disseram que para as mulheres a carreira se define de uma forma diferente. O destaque não é "acelerar", senão a possibilidade de ampliar o próprio horizonte dos conhecimentos e, eventualmente, ainda curtir seus resultados. Aqui se mostra novamente, que para as mulheres a profissão, assim como o estudo, tem uma função que serve para a auto-estima, que se expressa na vontade de aprender, na própria evolução e ampliação de suas perspectivas. Ou seja, enquanto os homens "têm que" se apressar em 
ter uma profissão e um emprego (e esta pressa é algo que está introjetado em suas mentes), as mulheres podem ir mais devagar e usufruir os conhecimentos adquiridos, sem a mesma pressão que se impõe aos homens.

Os rapazes do UTFPR também deram ênfase ao papel de provedor que lhes é imposto desde a mais tenra idade. Citaram casos familiares em que aprenderam com o exemplo de seus pais quais são suas obrigações. Para muitos, este é o seu projeto de vida. Diferentemente dos alemães, os rapazes brasileiros sonham em um dia ter um trabalho (para isto estão se preparando), ter uma família e poder sustentá-la sozinhos.

(...) o homem...sempre foi ter que cuidar de uma família e hoje em dia não é muito diferente disso não... têm que ter essa responsabilidade (...)

\section{(...)}

É um anseio meu de realização profissional conseguir atingir um cargo, um nível profissional, um patamar de poder sustentar minha família de uma maneira satisfatória, que eu possa dar o estudo, a casa, momentos de lazer para a família... acho que seria uma realização pessoal (...).

Alguns admitiram que suas futuras esposas poderão trabalhar (se quiserem), mas consideram que é mais importante que elas cuidem da família. Por outro lado, acham também que hoje em dia é praticamente impossível não precisar contar com a "ajuda" financeira da mulher, mas em suas representações esta não é a solução ideal."O problema disso é que as mulheres estão se afastando da família. Os filhos não estão sendo bem criados e crescidos". No caso das representações dos estudantes brasileiros foi possível perceber que não há a mesma rigidez acentuada pelos alemães, quanto às pressões para desempenharem o papel de provedor. Pode-se alegar que há uma maior flexibilidade em sua maneira de ser, porém não se pode esquecer das especificidades encontradas na organização familiar brasileira que criam outras possibilidades para os homens. 
Alguns estudantes comentaram, inclusive, que os padrões relativos ao papel de provedor estão mudando, e a forma tradicional não precisa necessariamente ser reproduzida. Segundo estes, "depende muito da cabeça de cada um". Neste caso, se a pessoa está trabalhando e tiver filhos, vai ter que entrar num acordo com o parceiro para saber quem cuidará da criança. "Se eu for casado e nós dois trabalhando (...) Eu acho que um dos dois vai ter que largar o emprego (...) ou trabalhar meio período pra ajudar". Porém foram poucos os que admitiram fazer o trabalho doméstico.

Vale lembrar que os possíveis conflitos oriundos deste impasse podem ser solucionados com o auxílio de empregadas domésticas e babás, no cumprimento das tarefas domésticas, especialmente em grupos correspondentes às camadas médias (CARVALHO, 1992). Nas camadas populares, as mulheres que trabalham fora de casa contam com a ajuda de outras mulheres de seu grupo de relações pessoais (mãe, sogra, irmã, cunhada, filhas mais velhas, vizinhas, etc.) para cuidarem de seus filhos (CARVALHO e CRAVO, 1988). Convém salientar que este é um arranjo pouco comum entre mulheres na Alemanha e que no Brasil, contribui para a reprodução do padrão tradicional de gênero em que o cuidado dos filhos e da casa é tarefa feminina.

\section{COMPETÊNCIA PROFISSIONAL E DESIGUALDADES DE GÊNERO}

Com relação à conquista do mercado de trabalho pelas mulheres, as opiniões dos rapazes brasileiros foi diferente do que se encontrou nos resultados da pesquisa em FHF. Pelas exigências crescentes no mundo do trabalho e por causa da redução dos postos de emprego, as diferenças entre os sexos na perspectiva dos/das participantes são niveladas, pois ambos devem igualmente se empenhar ou "se virar" para conquistar uma colocação no mercado.

De qualquer forma, há muito tempo as tendências de individualização têm influenciado a geração pesquisada em ambos os países, tanto no currículo como no planejamento. 
Uma observação dos relacionamentos entre os sexos na transição para a profissão no caso da Alemanha, resulta que, atualmente se trata de alianças e não mais de diferenças. Isto explica, por que pelo menos no nível retórico, nem os rapazes nem as moças consideram que as diferenças entre eles sejam importantes para o trabalho. Ambos têm que trabalhar igual. Diferenças típicas por sexo são minimizadas retoricamente ou banalizadas, tanto quanto se pode. Por causa da necessidade de se auto-afirmar, acontece um nivelamento das diferenças entre os sexos, porque "(...) na verdade importa, o quanto se é bom ou ruim".

As falas apontam para um encobrimento dos sexos (tendência a não enxergar as diferenças), para a busca de resultados - o que leva à formação de alianças que nivelam as diferenças já que o que importa é a competência. E, no Brasil, o quadro se repete ou também está ligado ao discurso do politicamente correto, onde a alegada "modernidade" do curso dificulta a exteriorização de desigualdades tradicionais de gênero?

A competição e as dificuldades de encontrar um espaço no mercado de trabalho estão gerando entre os rapazes brasileiros opiniões ambíguas e contraditórias. Percebe-se uma preocupação em não demonstrar um pensamento machista, porém muitas vezes ouviu-se frases como: “... acredito que tá certo que elas têm que trabalhar também, não é só a gente... Mas elas deviam ficar nos cargos menores (...) deixar os cargos mais altos pro marido receber mais”. Ou afirmações como esta: “com a revolução industrial resolveram inundar o mercado [de trabalho] com mulher, questão de mão-de-obra barata...". Segundo eles, muitas mulheres querem trabalhar e não percebem que recebem rendimento menor do que os homens pelo mesmo cargo.

As moças brasileiras têm plena consciência das dificuldades que irão enfrentar no competitivo mercado de trabalho e da desvantagem que levam pelo fato de serem mulheres. Com relação à busca por estágios no curso elas já sentem a discriminação quando são preteridas para a contratação dos colegas. "Muitas vezes a gente leva o curriculum para tratar de estágio e eles não te chamam e você não sabe porque, você chega de manhã, fica pensando se está faltando alguma coisa ou se é porque você é mulher, e a gente nem sabe porque na verdade a gente é eliminada primeiro". 
Também apontaram que há casos em que realizam o mesmo trabalho dos colegas e ganham menos. Apesar de a lei no Brasil não permitir este tipo de discriminação, tudo indica que nem sempre ela é cumprida. Algumas entrevistadas acreditam que o fato delas não serem reconhecidas como profissionais competentes na área técnica (o que não significa que não o sejam) pode ser um dos elementos que contribui para as diferenças de remuneração entre homens e mulheres “(...) o menino é o que mais ganhava, talvez por ele saber mexer com o programa (...) acho que pelo fato do domínio desta ferramenta (...)”.

O pagamento de menor valor para as mulheres como remuneração pelo mesmo trabalho realizado por um homem foi apontado por todos os entrevistados da UTFPR. Esta questão não surgiu em nenhum momento no artigo sobre os/as estudantes da Alemanha.

\section{GÊNERO E DIVERSIDADE CULTURAL}

A construção cultural do Brasil e da Alemanha se dá a partir de parâmetros diferentes. As análises e reflexões propostas até aqui também podem ser avaliadas dentro deste contexto, uma vez que o mesmo serve de pano de fundo para formação das identidades individuais.

Assim, algumas destas características podem estar ligadas às concepções que estas sociedades têm de tempo e espaço. Neste sentido, é possível relacionar as falas que apontam a incapacidade dos estudantes alemães de lidarem com vida profissional e constituição de uma família simultaneamente com a tendência monocrônica da cultura alemã.

Os rapazes, dentro do seu contexto cultural, sentem a necessidade de estabelecer projetos de vida de longo prazo. Uma vez eleitas suas metas, seguem escrupulosamente os programas estabelecidos. Assim, se optam pela vida profissional, tendem a estabelecer relacionamentos passageiros e transitórios, evitando as ligações mais estáveis e duradouras.

Este conjunto de características associado aos papéis masculinos na Alemanha, também pode ser interpretado à luz do seu processo sóciohistórico. Os rapazes sentem que devem ocupar com sucesso o seu lugar dentro da cadeia produtiva. O modelo liberal adotado pelo País reforça 
comportamentos individualistas, abrindo poucas possibilidades para outras conformações identitárias.

Tal configuração não foge ao modelo geral vivenciado no ocidente que reserva o mundo público para os homens e o privado para as mulheres. No que se refere às estudantes alemãs, a construção de suas identidades se dá dentro de um horizonte de possibilidades estabelecidas de antemão para o seu gênero.

É compreensível, então, que as mulheres encontrem dificuldades para conciliar carreira e vida familiar, já que terão de superar, entre outras coisas, o aspecto monocrônico da sua cultura a fim de poder estabelecer estratégias duplas para a construção de identidades como profissionais e como mães.

No entanto, quando são forçadas a superar as já citadas dificuldades na busca de formação para a vida profissional, se valeriam das características gerais da cultura alemã, tais como disciplina, aplicação, exatidão, pontualidade para serem aceitas num ambiente eminentemente masculino. Uma vez conquistadas tais competências, teriam condições de igualdade no mercado, já que este procura se orientar por princípios liberais. Neste contexto, o gênero fica em segundo plano, valendo mais a competência.

Como já apontado anteriormente, a cultura alemã apresenta um caráter relativamente unívoco no que se refere a estruturas e modelos de comportamento e, pelo que foi apresentado pela pesquisa na Alemanha, os papéis de gênero não fogem a esta conformação.

No tocante ao Brasil, as várias matrizes culturais podem apontar um caminho para a compreensão da maior flexibilidade dos comportamentos como um todo. Esta maleabilidade se revela no caráter policrônico da cultura brasileira. Isto fica evidente nas falas dos rapazes que procuram sucesso profissional exatamente para poderem constituir família e nelas desempenharem o papel de provedor.

Outro dado importante para compreensão dos papéis de gênero entre os estudantes brasileiros é a construção histórica da família na qual a autoridade paterna é vista como modelo de referência para a formação de identidades. Embora o mesmo não seja o único, tudo indica que é o ponto norteador das representações de gênero coletadas na pesquisa brasileira 
entre os rapazes. Isto aparece no caráter tradicional que eles apontaram para instituições como a família e o trabalho, mesmo que seja aparentemente contraditório com a visão de modernidade que os brasileiros atribuíram ao curso e à profissão que escolheram. Aqui se ressalta o caráter ambíguo da cultura brasileira ${ }^{23}$.

Com relação às mulheres, num primeiro momento, pode-se ressaltar que sua presença crescente nos cursos da área tecnológica significaria uma mudança com relação a este modelo. No entanto, esta visão progressista em relação ao papel da mulher pode ser relativizada pelo fato de que a inclusão da mesma no mercado de trabalho não a exclui, necessariamente, do papel de mãe, nem da dupla jornada de trabalho inerente a ele - embora tenha havido um silêncio das informantes sobre como vêem as relações entre família e trabalho.

\section{PARA FINALIZAR...}

A perspectiva comparativa é eficaz para se compreender as semelhanças e diferenças a respeito das representações de gênero nos cursos da área tecnológica entre os/as estudantes do Brasil e da Alemanha dentro de um contexto de diversidade cultural.

Esta pesquisa revelou que há muitos pontos em comum entre os dois países, porém há também divergências. Ambas estão relacionadas às características culturais dos países envolvidos.

Com relação a gênero e suas interações com o domínio da técnica, tanto os/as brasileiros/as quanto os/as alemães/ãs consideram que os homens têm melhor desempenho técnico quando comparados às mulheres. O processo de socialização dos meninos nos dois países influiu de maneira significativa para marcar esta diferença que pode ser interpretada como uma desvantagem para as mulheres em ambientes onde o conhecimento técnico seja fundamental.

No caso da Alemanha, pode-se dizer que o preconceito com relação às mulheres é mais acentuado porque elas são consideradas incompetentes 
tecnicamente e não são aceitas neste domínio. No caso brasileiro, a rigidez não é tão visível, e os rapazes admitem outras possibilidades para as mulheres, revelando que elas têm competência para outras áreas para as quais eles nem sempre possuem.

Por outro lado, no mercado de trabalho alemão, há uma maior igualdade entre as chances de trabalho e a remuneração de homens e mulheres. Com a competição acirrada e as dificuldades de emprego cada vez maiores, a pesquisa na FHF revelou que na Alemanha importa mais a competência do trabalhador do que o sexo. Na verdade, esta questão não está resolvida porque há ainda muita polêmica em torno das mudanças e permanências de padrões tradicionais de gênero neste âmbito. No Brasil, a discriminação da mulher no mercado de trabalho em áreas técnicas é explícita não só com relação à busca de emprego, mas também com relação à remuneração.

Os resultados da pesquisa no Brasil permitem dizer que os brasileiros têm planos diferentes dos alemães com relação a futuro e vida familiar. Percebe-se que entre os alemães o individualismo está mais presente e se manifesta de maneira clara e visível, através das perspectivas de vida, mas também quanto a crítica às pressões a que estão sujeitos para reproduzirem um padrão masculino que consideram pesado e de muita pressão. Por esta razão não manifestaram desejo de constituir família, pois isto para eles significa uma carga a mais a enfrentar na vida. Por isso não pensam em uniões estáveis, revelando-se, quanto a este aspecto, o caráter monocrônico da cultura alemã.

No Brasil, os depoimentos sobre a vida futura quanto ao trabalho e à família foram diferentes. Esta diferença tem relação direta com a diversidade cultural entre os dois países. A família no Brasil é um valor que está presente de uma maneira muito forte praticamente em toda a população e o trabalho representa a possibilidade de ter uma vida familiar de acordo com as expectativas sociais (CARVALHO, 1992). Os planos são pensados com vista a este valor cultural e as construções de gênero estão diretamente ligadas a este projeto. A correlação entre família e trabalho como algo desejável para os jovens pode ser interpretada como um traço cultural policrônico, mais presente no comportamento dos brasileiros. 
Esta pesquisa revelou ainda que os padrões tradicionais de gênero estão em processo de transformação e, como todo o processo de mudança possui contradições e ambigüidades que estão presentes nos depoimentos dos entrevistados. Ora a igualdade de gênero é vivenciada e as diferenças são sequer percebidas, ora a desigualdade e o preconceito brotam de maneira forte e rígida a ponto de revelar comportamentos discriminatórios e preconceituosos. Estas oscilações nas representações sobre gênero entre a igualdade/desigualdade, o velho e o novo, a tradição e a modernidade estão presentes entre os estudantes de ambos os países pesquisados.

$\mathrm{Na}$ área tecnológica ainda há muito que mudar. $\mathrm{O}$ aumento do número de mulheres nestes cursos é importante para tal transformação. Porém, o fator quantitativo por si só não tem alterado as relações desiguais de gênero nos cursos tecnológicos e muito menos no mercado de trabalho. Para que haja mudança em direção à eqüidade de gênero, é necessário, entre outras práticas, modificar também o processo de socialização de meninos e meninas para que ambos cheguem aos cursos técnicos com as mesmas habilidades e as mesmas chances.

Além disso, é preciso que uma mudança cultural mais profunda ocorra em ambas as sociedades a fim de que sejam criadas condições para a construção de uma perspectiva crítica ao sistema social mais amplo, que "escraviza" igualmente homens e mulheres na medida em que impõe a subordinação ao conhecimento tecnológico instrumental como única forma de realização humana.

\section{REFERÊNCIAS}

CARVALHO, M. G. e CRAVO, V. Z. Antes mal-acompanhada do que só: estudo de relações familiaresem grupos matrifociais. In Boletim de Antropologia. nova série 3. Departamento de Antropologia. Setor de Ciências Humanas. Letras e Artes. UFPR, abril, 1988.

\section{CARVALHO, M. G. As vicissitudes da família na sociedade moderna: estudo sobre o casamento e relações familiares. Tese de doutorado em Antropologia Social. USP, 2002.}


CARVALHO, M. G. Diversidad cultural y el proceso de construcción de género en el mundo técnico: el caso de Brasil y Alemania. In: CARVALHO, M.G. e TAMANINI, M. (organizadoras). Diversidad cultural, género y tecnología: un abordaje interdisciplinario. Curitiba: UTFPR, 2006.

CORREA, M. "Repensando a família patriarcal brasileira”, em Colcha de Retalhos.São Paulo: Brasiliense, 1982.

DA MATTA, R. Você sabe com quem está falando? Um ensaio sobre a distinção entre indivíduo e pessoa no Brasil. In: Carnavais, malandros e heróis. Rio de Janeiro: Zahar, 1980.

. 0 que faz o brasil, Brasil? Rio de Janeiro: Rocco, 1986.

HALL, E. T. et HALL, M. R. Guide du comportement dans les affaires internationales - Allemagne, Etats-Unis, France. Editions du Seuil, 1990.

LOURO, Guacira Lopes. Gênero, sexualidade e educação. Petrópolis: Vozes, 2001.

MUNDER, Irmtraud e CARVALHO, Marilia Gomes de et al. "Mujeres y estudios técnicos, ¿conceptos compatibles? Tentativa de una comparación intercultural entre Alemania y Brasil”. V CONGRESO IBEROAMÉRICANO “CIENCIA, TECNOLOGÍA Y GÉNERO”, 2004, Cidade do México, In: Cadernos de Gênero e Tecnologia, no. 1. Curitiba: Ed. CEFET-PR, 2005.

PATEAU, J. Aproche comparative interculturelle: étude d'enterprises française et alemandes. These de Doctorat. UNIVERSITE DE PARIS X NANTERRE - Études Germaniques, 1994.

PRADO JR, Caio. A formação do Brasil contemporâneo. São Paulo: Brasiliense, 1971. 
RIBEIRO, Darci. O povo brasileiro - a formação e o sentido do Brasil. 2a ed. São Paulo: Cia das Letras, 1995.

SCOTT, Joan. "Gênero: uma categoria útil de análise histórica". In Educação e realidade: gênero e educação. Porto Alegre. v. 20, n. 2, jul/dez, 1995.

TREVISAN, Lino. Interculturalidade no ambiente empresarial: relações entre brasileiros e estrangeiros na Volkswagen / Audi de São José dos Pinhais - PR. Dissertação de Mestrado. PPGTE/CEFET-PR, 2001. 
